\title{
THE EFFECT OF CARDIAC SURGERY ON PERIPHERAL BLOOD LYMPHOCYTE POPULATIONS
}

\author{
Karolína Jankovičová1, Manuela Trojáčková Kudlová ${ }^{1}$, Martina Koláčková1, Pavel Kuneš ${ }^{1,2}$, Jiři Mand’ák ${ }^{2}$, \\ Vladimír Lonský2, Dana Vláškován ${ }^{2}$ Ctirad Andrýs ${ }^{1}$, Jan Krejsek ${ }^{1}$
}

Charles University in Prague, Faculty of Medicine and University Hospital Hradec Králové, Czech Republic: Department of Clinical Immunology and Allergology ${ }^{1}$, Department of Cardiac Surgery ${ }^{2}$

\begin{abstract}
Summary: Background: Cardiac surgery using cardiopulmonary bypass (CPB) is associated with some adverse postoperative complications caused by an altered immune response. An alternative approach to cardiac surgery, operating without the use of CPB (i.e. off-pump surgery), seems to display less adverse impacts on the immune response. Patients and Methods: Peripheral blood lymphocytes in 40 patients undergoing cardiac surgery either with CPB ("on-pump") or without CPB ("off-pump") were followed using flow cytometry. The samples of peripheral blood were taken at five intervals: preoperatively, after termination of the surgery, on the first, on the third and on the seventh postoperative day, respectively. Results: The most substantial changes appeared on the first postoperative day in both subgroups of patients. While the percentage of both total $\mathrm{T}$ cells and $\mathrm{CD} 4^{+} \mathrm{T}$ cells were decreased, the percentage of HLA-DR ${ }^{+}$activated lymphocytes was increased. These changes were more profound in the "on-pump" subgroup compared to the "off-pump" subgroup. Conclusion: Our results may suggest that the "off-pump" surgical approach reveals less adverse impact on adaptive immune responses.
\end{abstract}

Key words: Cardiac surgery; CPB (cardiopulmonary bypass); Beating heart surgery; Lymphocytes; Flow cytometry

\section{Introduction}

Cardiac surgical operations are followed by numerous changes in the immune reactivity $(4,18)$. Massive activation of innate immunity very early during cardiac surgery is elicited by the extensive exposure of this branch of immunity to "danger" signals which emanate from body integrity destruction, tissue and organ hypoperfusion, followed by an exaggerated reactive oxygen species generation and decreased barrier functions of gut mucosa to emphasize only some of many. Moreover, in "on pump" patients overwhelming contact activation of both humoral and cellular components of blood has to be added to the top of the complex list of adverse effects raised during cardiac surgery. Adaptive immunity, meaning $\mathrm{T}$ and $\mathrm{B}$ cell systems, is affected with some delay in the course of surgery, peaking in the early postoperative period. The dynamics of immune response is thus following the very nature of immune responses (17). Both activation and inhibition processes could be identified during cardiac surgery and in the course of postsurgical recovery. The optimal balance between these processes is the ultimate goal, leading to full recovery.

Two principally different attempts either using cardiopulmonary bypass (CPB) ("on-pump”) surgery or without such arteficial support, meaning beating heart surgery ("off- pump") are now being used (11). It is claimed that an extensive and sometimes overwhelming systemic inflammatory response (SIRS) followed by profound immune depression leading to severe infectious complications are due to CPB (22). Based on results of some studies, it is suggested that the beating heart surgery is superior to "on pump" surgery $(5,6)$. However, data which are gathered in this field are contradictory. Further work is necessary to reconcile these doubts.

At least transient lymphopenia and suppression of specific immunity is induced by anesthesia and any surgical operations $(13,14)$. Global immunosuppression elicited by "on-pump" cardiac surgery seems to be more profound compared to other types of surgery (18). Lymphopenia, which is typically seen during an early postoperative period in "off-pump" patiens, is especially caused by the reduction of $\mathrm{T}$ cell populations $(10,17)$. Whereas the number of $\mathrm{CD}^{+}$helper inducer $\mathrm{T}$ cells is significantly decreased, the number of $\mathrm{CD}^{+}$suppressor cytotoxic $\mathrm{T}$ cells is not affected or is even increased in the response to the cardiac surgery. As a result, the CD4/CD8 $\mathrm{T}$ cell ratio is substantially decreased $(13,17,21)$. There is a shift from Th1 subset activity to Th2 subset regulations mirrored by the changes in the spectrum of cytokines produced $(8,13,15,16,17)$. Regarding natural cytotoxicity mediated by NK cells, re- 
sults are contradictory. Both diminished NK cell numbers and activity or unaffected or even enhanced NK cell activity are mentioned by many authors $(1,13,18,19,21)$.

There is the consensus that "on-pump" surgery is associated with more extensive lymphocyte activation. The expression of numerous activation markers, such as an early activation molecule (AIM) CD69 and the late activation molecules HLA-DR and $\alpha$ subunit of IL-2 receptor (CD25), is increased in lymphocytes of cardiac surgical patients $(2,9,14,22,23,24)$.

In the context of our previous work dealing with different patterns of cytokine production in "on-pump" and "offpump" cardiac surgical patients (12), the aim of this study is focused on the changes of adaptive immunity cell substrate and the expression of activation markers on these cells in the course of cardiac surgery and during early the postoperative period.

\section{Patients}

Forty patients ( 31 male, mean age $67.9 \pm 9$ years and 9 female, mean age $66.4 \pm 6.4$ years, collective mean age 67.6 \pm 8.5 years) referred to first-time coronary artery bypass grafting were enrolled in this study. Patients underwent either conventional myocardial revascularization with cardiopulmonary bypass and cardioplegic arrest of the heart ("on-pump", n=20, 16 male, 4 females, mean age $69.4 \pm 7$ years) or beating heart surgery ("off-pump", $n=20,15$ males, 5 females, mean age $65.9 \pm 9.7$ years). The patients were randomly assigned either to "on-pump" or to "offpump" surgery by a member of the cardiac surgery staff outside the research team who was blinded to all variables pertinent to the study design.

Patients in both groups were comparable in age, preoperative left ventricular ejection fraction (median 0.65 in "on-pump", 0.65 in "off-pump" patients, respectively) and the number of performed coronary anastomoses (median 2.0 in "on-pump", 2.0 in "off-pump”, respectively).

The Ethics Committee of the University Hospital in Hradec Kralove approved the study protocol. Written informed consent was given by each participant.

\section{Blood sampling}

Peripheral venous blood from an antebrachial vein was withdrawn into heparinized testing tubes manufactured by Saarstedt (Germany) at the following time points: introduction to anaesthesia (sample 1), after termination of the operation (sample 2), the first postoperative day (sample 3 ), the third postoperative day (sample 4), and the seventh postoperative day (sample 5).

\section{Methods}

Direct double immunofluorescence whole blood lysing method was used. Lymphocytes were stained by monoclonal antibodies purchased from Immunotech (France): the following combinations of monoclonal antibodies CD19 FITC/CD5PE, CD3FITC/CD4PE, CD8FITC/CD56PE, CD3FITC/CD69PE, CD3FITC/HLADR-PE. To identify lymphoid cells precisely, the combination of CD45 FITC and CD14 PE monoclonal antibodies were used. Samples were analyzed by FACS Calibur flow cytometer (B.D., USA) using CELLQuest software.

\section{Statistical analysis}

Changes in the relative numbers of lymphocytes within a group and between both groups ("on-pump”, “off-pump”) were evaluated. Data were analyzed using ANOVA and post-hoc tests. The dynamics of changes is expressed as medians. A probability (p) value $<0.05$ was considered significant. Statistical analysis was performed with Statistica 5.5 software (Statsoft, USA).

\section{Results}

Significant differences in the relative number of $\mathrm{CD}^{+}$ lymphocytes were found. The relative number of $\mathrm{CD}^{+}$ lymphocytes in "on-pump" patients at the end of surgery was significantly lower compared to "off-pump" patients $(61.8 \%$ vs. $77.8 \%$, respectively; $\mathrm{p}<0.01)$. The nadir in the relative number of $\mathrm{CD}^{+}$lymphocytes was reached at the first postoperative day in both groups (54.8 \% in "on-pump"; $64.3 \%$ in „off-pump, respectively). There was a gradual increase in their numbers thereafter (Fig. 1). The same results were obtained by staining with monoclonal antibody against CD3.

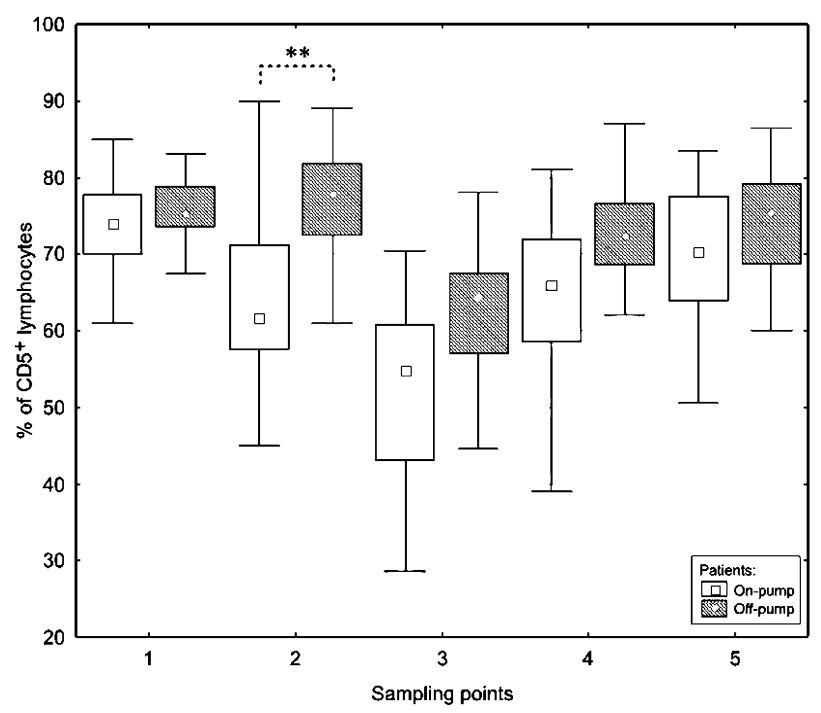

Fig. 1: The relative number of $\mathrm{CD} 5^{+}$lymphocytes in cardiac surgery patients ("on-pump" and "off-pump" group) in the course of surgery and in the early postoperative period (1 - introduction to anaesthesia, 2 - after termination of the operation, 3 - the first postoperative day, 4 - the third postoperative day, 5 - the seventh postoperative day), ** probability level 0.01-0.001). 
A similar pattern in the relative number of $\mathrm{CD}^{+}$helper inducer T cells both "on-pump" and "off-pump" patients was delineated by us. The relative number of $\mathrm{CD} 4^{+}$helper $\mathrm{T}$ cells was significantly decreased in "on-pump" patients

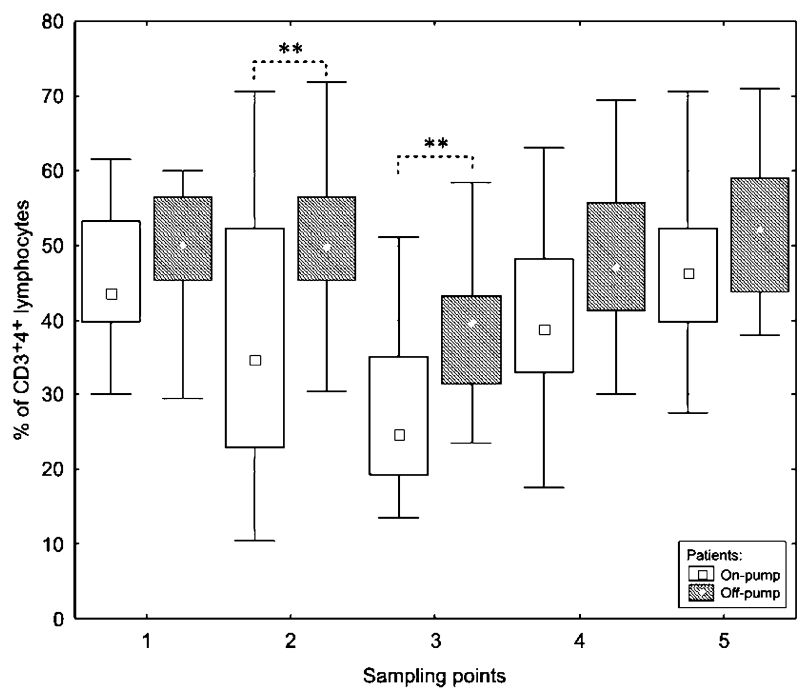

Fig. 2: The relative number of $\mathrm{CD}^{+} / \mathrm{CD} 4^{+}$lymphocytes in cardiac surgery patients ("on-pump" and "off-pump" group) in the course of surgery and in the early postoperative period ( 1 - introduction to anaesthesia, 2 - after termination of the operation, 3 - the first postoperative day, 4 - the third postoperative day, 5 - the seventh postoperative day), ** probability level 0.01-0.001).

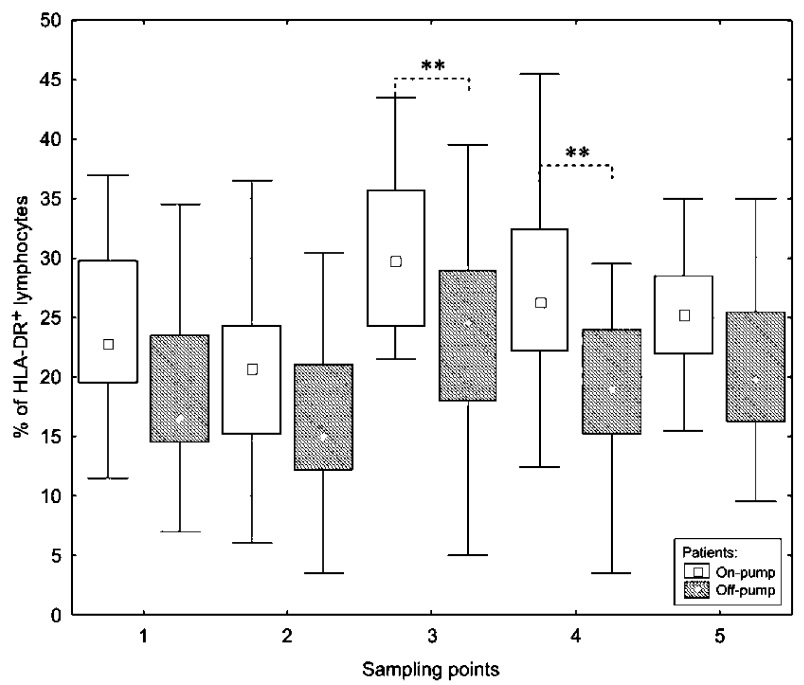

Fig. 3: The relative number of HLA-DR ${ }^{+}$lymphocytes in cardiac surgery patients ("on-pump" and "off-pump" group) in the course of surgery and in the early postoperative period ( 1 - introduction to anaesthesia, 2 - after termination of the operation, 3 - the first postoperative day, 4 - the third postoperative day, 5 - the seventh postoperative day), ${ }^{* *}$ probability level $0.01-0.001$ ).
(34.8\%) compared to "off-pump" patients $(49.8 \%$; $p<0.01)$ at the end of surgery. The relative number of $\mathrm{CD}^{+} \mathrm{T}$ cells was even lower at the first postoperative day, being significantly decreased in "on-pump" patients $(24.8 \%)$ compared to $39.5 \%$ in "off-pump"; $p<0.01$. The gradual recovery to the preoperative levels of $\mathrm{CD}^{+} \mathrm{T}$ cells was identified in both patient groups in the late postoperative period (Fig. 2).

There were no significant differences between "onpump" and "off-pump" patients regarding the relative number of $\mathrm{CD}^{+}$cells. Initially, there was a non-significant increase in their numbers during surgery, followed by a decrease in their relative numbers reaching statistical significance at the $7^{\text {th }}$ postoperative day for both groups.

Significant differences between "on-pump" and "offpump" patients were not found either in the case of CD56 $6^{+}$ $\mathrm{NK}$ cells. The maximum in the relative number of $\mathrm{CD} 56^{+}$ NK cells was reached at the first postoperative day, with a subsequent decrease in both groups.

The expression of an early activation marker CD69 was not influenced by cardiac surgery, being nonsignificantly different between "on-pump" and "off-pump" patients.

In contrast to this, the expression of the late activation marker HLA-DR on lymphocytes was significantly influenced by the different surgical approaches. The dynamics of HLA-DR expression on lymphocytes was similar for both groups, reaching the maximum at the first postoperative day. The number of HLA-DR ${ }^{+}$lymphocytes at the first postoperative day was higher in "on-pump" patients $(29.8 \%)$ compared to "off-pump" patients $(24.5 ; \mathrm{p}<0.01)$. A similar pattern was found also at the $3^{\text {rd }}$ postoperative day, being $26.3 \%$ for "on-pump" and $19.0 \%$ for "off-pump", respectively; $\mathrm{p}<0.01$. The maximum of HLA-DR ${ }^{+}$lymphocytes was reached on the $1^{\text {st }}$ postoperative day in both the "on-pump" and "off-pump" patients (Fig. 3).

\section{Discussion}

In agreement with others $(17,22)$, we found significantly lower numbers of $T$ cells in peripheral blood of cardiac surgical patients in the postoperative period. The nadir in the relative number of $T$ cells was reached on the $1^{\text {st }}$ postoperative day in both "on-pump" and "off-pump" patients. The same pattern was found also in the case of $\mathrm{CD} 4^{+}$helper inducer $T$ cells in accordance with previous studies $(4,13$, 17). The population of $\mathrm{CD} 8^{+}$cells is covers predominantly cytotoxic suppressor $\mathrm{T}$ cells but small populations of natural cytotoxic NK cells expressing CD8 are also included. There was a gradual decrease in both $\mathrm{CD} 8^{+}$cells and NK cell populations in the entire postoperative period, reaching a minimum on the $7^{\text {th }}$ postoperative day, being nonsignificantly different between "on-pump" and "off-pump" patients. This pattern is in contrast to the very rapid decrease in the relative number of $\mathrm{CD} 4^{+}$helper $\mathrm{T}$ cells which reached their minimum already on the $1^{\text {st }}$ postoperative day. Based on the previous fact, there is a decrease in the value of the 
immunoregulatory index as shown by others $(13,18,21$, $23)$. These changes are not caused by the haemodilution during surgery as proven by others $(8,21)$. It is suggested that both redistribution between peripheral blood and bone marrow pools, together with tissue sequestration of activated lymphocytes subsets, are reasons for this $(10,13)$.

We also followed the activation of lymphocytes after cardiac surgical operation. We did not found any significant changes in the expression of the C-lectin type early activation molecule CD69 in either "on-pump" or "off-pump" surgery. In contrast, there was a significant increase in the expression of a late HLA-DR activation marker in the postoperative period in both groups of patients, reaching a maximum on the first postoperative day. An increased number of activated lymphocytes in "on-pump" patients has been published by others, but such studies in "offpump" patients are very sparse $(8,21,22,23)$. It was proven that lymphocyte activation is functionaly linked to anergy and apoptosis of T cells, especially Th1 subset helper - inducer $\mathrm{T}$ cells and cytotoxic $\mathrm{CD} 8^{+} \mathrm{T}$ cells $(4,8,14$, 20). As a consequence of this, there is a substantial shift towards Th2 - driven immune response in "on-pump" patients as seen from cytokine patterns $(3,13,15,16,17)$. This shift from Th1 - driven cytotoxic reactivity with many potentially adverse effects on body structures toward Th2 driven response, culminating in much more mild humoral response and production of antiinflammatory mediators such as IL-10, has to be recognized as a principal regulatory and homeostatic mechanism to maintain body homeostasis.

One of the principal aims of our study was to discover if there are different variables, inducing lymphocyte activation, raised by different surgical approaches. Data from this are discordant. It was claimed by Abbas (1) and Gasz (9) that "on-pump" surgery is associated with more profound changes compared to "off-pump" surgery. In contrary, Diegeler (6), Blacher (2), and Franke (7) are in aggreement that activation of immune response is comparable regardless of "on-pump" or "off-pump" surgical approaches. It seems from their results that the very surgical trauma itself is the most important variable.

It could be summarized from our results that there are substantial changes in lymphocyte populations in both "onpump" and "off-pump" patiens, being more profound in former group. The majority of these changes was found on the first postoperative day on which significantly lower level of $\mathrm{CD}^{+}$helper $\mathrm{T}$ cells and a significantly higher number of HLA-DR expressing lymphocytes in "on-pump" patients were identified.

Predominantly antiinflammatory and immunosuppressive mechanisms which are typical for an early postoperative period in cardiac surgical patients are associated with enhanced risk of infection complications $(4,18,19,22)$. To overcome such transiently impared immune response in cardiac surgical patients some immunomodulatory interventions have been recently discussed (16). Our work adds some data to favour the opinion that some alternative surgical approaches could attenuate adverse effects of cardiac surgery on lymphocyte populations.

\section{Acknowledgments}

This work was supported by a research program of The Czech Ministry of Youth, School and Physical Activities, School and Physical Activities No. MSM 0021620812 and Internal Grant Agency of Ministry of Health, Czech Republic, No. NR/9090-4.

Authors are in debt to Jaroslav Kubicek and Martin Volt, perfusionists both in the staff of Dept. of Cardiac Surgery for their support of this study.

\section{References}

1. Akbas H, Erdal AC, Demiralp E, Alp M. Effects of coronary artery bypass grafting on cellular immunity with or without cardiopulmonary bypass: changes in lymphocytes subsets. Cardiovasc Surg 2002;10:586-9.

2. Blacher C, Neumann J, Jung LA, Lucchese FA, Ribeiro JP. Off-pump coronary artery bypass grafting does not reduce lymphocyte activation. Int J Cardiol 2005;101:473-9.

3. De AK, Kodys KM, Pellegrini J, Yeh B, Furse RK, Bankey P, Miller-Graziano CL. Induction of global anergy rather than inhibitory Th2 lymphokines mediates posttrauma T cell immunodepression. Clin Immunol 2000;96:52-66.

4. Delogu G, Moretti S, Antonucci A et al. Apoptosis and surgical trauma. Arch Surg 2000;135:1141-7.

5. Diegeler A, Doll N, Rauch $\mathrm{T}$ et al. Humoral immune response during coronary artery bypass grafting. A comparison of limited approach, "off-pump" technique, and conventional cardiopulmonary bypass. Circulation 2000;102(suppl 3):95-100

6. Diegeler A, Tárnok A, Rauch T et al. Changes of leukocyte subsets in coronary artery bypass surgery: cardiopulmonary bypass versus "off-pump" techniques. Thorac Cardiovasc Surg 1998;46:327-32.

7. Franke A, Lante W, Fackeldey V et al. Pro-inflammatory cytokines after different kinds of cardio-thoracic surgical procedures: is what we see what we know? Eur J Cardiothorac Surg 2005;28:569-75.

8. Franke A, Lante W, Kurig E, Zöller JG, Weinhold C, Markewitz A Hyporesponsiveness of $\mathrm{T}$ cell subsets after cardiac surgery: a product of altered cell function or merely a result of absolute cell count changes in peripheral blood? Eur J Cardiothorac Surg 2006;30:64-71.

9. Gasz B, Lenard L, Benko L et al. Expression of CD97 and adhesion molecules on circulating leukocytes in patients undergoing coronary artery bypass surgery. Eur Surg Res 2005;37:281-9.

10. Ide H, Kakiuchi T, Furuta $\mathrm{N}$ et al. The effect of cardiopulmonary bypass on T cells and their subpopulations. Ann Thorac Surg 1987;44:277-82.

11. Khan NE, de Souza A, Mister R et al. A randomized comparison of off-pump and on-pump multivessel coronary-artery bypass surgery. N Engl J Med 2004;350: 21-8.

12. Kudlová M, Koláčková M, Kuneš $\mathrm{P}$ et al. Cardiac surgery operations and their influence on serum level of antiinflammatory cytokine interleukin-10. Cas Lek Ces 2007; 146:48-55

13. Kuneš P, Krejsek J. CD4 lymphopenia and postoperative immunosuppression in cardiac surgery. Cas Lek Ces 2000;139:361-8.

14. Leaes PE, Neumann J, Jung LA, Blacher C, Lucchese F, Clausell N. Lymphocyte's activation and apoptosis after coronary artery bypass graft: a comparative study of two membrane oxygenators - one with and another without a venous-arterial shunt. ASAIO J 2004:50:611-18.

15. Lante W, Franke A, Weinhold C, Markewitz A. Immunoglobulin levels and lymphocyte subsets following cardiac operations: further evidence for a T-helper cell shifting. Thorac Cardiovasc Surg 2005;53:16-22.

16. Markewitz A, Faist E, Lang S, Hültner L, Weinhold C, Reichart B. An imbalance in T-helper cell subsets alters immune response after cardiac surgery. Eur J Cardiothorac Surg 1996;10:61-7.

17. Markewitz A, Lante W, Franke A, Marohl K, Kuhlmann WD, Weihnold C. Alterations of cell-mediated immunity following cardiac operations: clinical implications and open questions. Shock 2001;16(suppl 1):10-15.

18. Naldini A, Borrelli E, Cesari S, Giomarelli P, Toscano M. In vitro cytokine production and T-cell proliferation in patients undergoing cardiopulmonary by-pass. Cytokine 1995;7:165-170. 
19. Nguyen DM, Mulder DS, Shennib H. Effect of cardiopulmonary bypass on circulating lymphocyte function. Ann Thorac Surg 1992;53:611-16.

20. Pellegrini JD, De AK, Kodys K, Puyana JC, Furse RK, Miller-Graziano C. Relationships between $\mathrm{T}$ lymphocyte apoptosis and anergy following trauma J Surg Res 2000;88:200-206.

21. Perttilä J, Salo M, Pirttikangas C-O, Jalonen J, Vainio O. Effects of cardiopulmonary bypass on lymphocytes and their subsets counts with or without use of autotransfusion devices. J Cardiothorac Vasc Anesth 1994;8:532-5.

22. Rinder CS, Matthew JP, Rinder HM, Tracey JB, Davis E, Smith BR. Lymphocyte and monocyte subset changes during cardiopulmonary bypass: effects of aging and gender. J Lab Clin Med 1997;129:592-602.

23. Sharma M, Ganguly NK, Chaturvedi G, Thingnam SKS, Majumdar S, Suri RK. Release of pro-inflammatory mediators during myocardial ischemia/reperfusion in coronary artery bypass graft surgery. Mol Cell Biochem 2003;247: $23-30$.

24. Shimaoka M, Hosotsubo K, Sugimoto M et al. The influence of surgical stress on T cells: Enhancement of early phase lymphocyte activation. Anesth Analg 1998; 87:1431-5.

Submitted February 2008. Accepted March 2008

\section{Corresponding author:}

Prof. RNDr. Jan Krejsek, CSc., Department of Clinical Immunology and Allergology, University Hospital, Sokolská 581, 50005 Hradec Kralové, Czech Republic, e-mail: krejsek@fnhk.cz 